\title{
ESTUDIOS SOBRE LAS RUBIÁCEAS DE MÉXICO, LI Una especie nueva del género Mitracarpus (Spermacoceae, Rubiaceae) en Oaxaca y Tabasco
}

\author{
A. Borhidi ${ }^{1}$ y E. Martínez SAlas ${ }^{2}$ \\ ${ }^{1}$ Departamento de Fitotaxonomía y Geobotánica, Instituto de Biología, Universidad de Pécs \\ H-7624 Pécs, Ifjúság útja 6, Hungría; E-mail: borhidi@gamma.ttk.pte.hu \\ ${ }^{2}$ Instituto de Biología, Universidad Autónoma de México (UNAM), México \\ E-mail:ems@ib.unam.mx
}

(Received 4 November, 2014; Accepted 15 December, 2014)

The new species of Mitracarpus of Oaxaca y Tabasco is prominent of its extremely small flowers almost completely hidden among the longer calyx lobes. It differs from Mitracarpus breviflorus A. Gray, the other small-flowered species of the genus, by being a perennial herb with 4-angular hairy stems lignescent at the base and the larger, elliptical, 5-7-nerved leaves.

Key words: Mexico, Mitracarpus, Oaxaca y Tabasco, Rubiaceae, small-flowered

Mitracarpus micranthus Borhidi et E. Martínez, spec. nova, hoc loco

Tipo: México, Tabasco, Mpio. Paraíso, en el 21 km de la carretera de Paraíso a la Barra de Tupilco a $1 \mathrm{~m}$ snm. dentro del cocotero, asociada con Senna y Mollugo. Col.: M. A. Magaña (1439), 17.03.1986. Holotipo: MEXU.

Herba perennis 25-35 cm alta, caulis basi lignosus, cylindraceus, glabrescentes, inferne nitidus, superne angulatus et anguste alatus, in angulis pilis longis retrorsis patenter pilosus inter angulos tomentulosus. Nodi distantes, internodii 7-10 cm longi. Stipulae ad nodos dilatatae, petiolis $1.5 \mathrm{~mm}$ longe connatae, hyalinae, albae, extus sparse pilosae, pars libera truncata, aristis 5-8, 1-2 mm longis, apice glandulosis, collateribus nonnullis intercalatis. Folia ovata vel elliptica, sessilia, 2-5 cm longa et 0.8-2 cm lata, basi 5-7-nervia, papyracea vel blanda, apice obtusa vel acuta, basi obtusa, supra sparse scabrosule brevi-pilosa, subtus ad nervos vix pilosa cum aetate glabrescentia vel glabra, margine estrigoso-hispidula; nervo medio supra impresso, subtus prominente, nervi laterales additionales ad basales supra omnes obsoleti, subtus prominentes. Inflorescentiae in capitulis densis terminalibus et in quasi omnibus 
nodis, terminales 1, axillares $1.5 \mathrm{~cm}$ latis, terminales cum 4, axillares cum 2 bracteis foliaceis suffulti et cum stipulis in involucrum connatis. Flores albi vel purpurascentes, rariter cum centro viride colorati. Hypanthium supra medio pilosum. Calyx 4-lobulatus, basi breviter connatus, lobi majores 2, virides, lanceolati, $2 \mathrm{~mm}$ longi, plerumque leviter inaequales, acuti et apiculati, extus pilosi, intus glabri, minores hyalini, membranacei, tenuissimi, oblongo triangulares, acuti, $1 \mathrm{~mm}$ longi, omnes margine fimbriati. Corolla $2 \mathrm{~mm}$ longa, plerumque inter lobos calycis occulta, tubus $1.5 \mathrm{~mm}$ longus utrinque glaber, lobi 4 , ovati vel semiorbiculares, $0.5 \mathrm{~mm}$ longi, apice rotundati, extus minutissime puberuli, intus glabri. Stamina 4, antherae sessiles in sinubus loborum corollinorum, late ellipticae, $0.2 \mathrm{~mm}$ longae. Stylus $1 \mathrm{~mm}$ longus in tubum corollae inclusus. Fructus capsula membranacea, bilocular, $1.5 \mathrm{~mm}$ longa et 1.5-1.7 mm lata, supra medio puberula, circumscissa. Semina flavescentia vel orangeato-brunnea, ovata vel suborbicularia, dorso minute tuberculata depressionem cruciformem carentia, cum 4 sulcis profundis ventralibus " $x$ " formatis.

Hierba perenne de $25-35 \mathrm{~cm}$ de alta, tallos leñosos en la base, cilíndricos glabrescentes y nítidos abajo, angulosos y estrechamente alados y extendido pelosos arriba con pelos largos retrorsos en los ángulos y tomentosulos entre los ángulos. Nodos distantes, entrenudos de 7-10 cm de largo. Estípulas ensanchadas en los nudos, connadas con los pecíolos en $1.5 \mathrm{~mm}$ de largo, hialínos, blancos, esparcido pelosos por fuera, la parte libre truncada con 5-8 aristas de 1 a $2 \mathrm{~mm}$ de largo con algunos coléteros intercalados, glandulosos en el ápice. Hojas 5-7-nervias desde la base, ovales a elípticas, sésiles, de 2 a 5 $\mathrm{cm}$ de largo y 0.8 a $2 \mathrm{~cm}$ de ancho, papíráceas o suaves, agudas u obtusas en el ápice, obtusas en la base, esparcidamente escabroso corto pelosas en el haz, algo pelosas en los nervios del envés, glabrescentes a glabras con la edad, híspidas en el margen estrigoso; nervio medio hundido en el haz, prominente en el envés nervios laterales 1-2 pares adicionales a los basales, todos obsoletos en el haz, prominentes en el envés. Inflorescencias en capítulos densos en casi todos los nudos a lo largo del tallo, los terminales de $1 \mathrm{~cm}$, las axilares de hasta $1.5 \mathrm{~cm}$ de ancho, las terminales con 4 , las axilares con 2 brácteas connadas en el involucro formado por las estípulas. Flores blancas o moradas, a veces con centro de color verde. Hipanto peloso sobre la mitad. Cáliz 4-lobado, lobos brevemente connados en la base, con 2 lóbulos mayores, verdes, lanceolados, de $2 \mathrm{~mm}$ de largo, a menudo poco desiguales, agudos y apiculados, pelosos por fuera, glabros por dentro, los menores hialinos, membranosos, muy delgados oblongo-triangulares, agudos, de $1 \mathrm{~mm}$ de largo, todos fimbriados en el margen. Corola de $2 \mathrm{~mm}$ de largo, mayormente esta hundida entre los lóbulos del cáliz; el tubo de $1.5 \mathrm{~mm}$ de largo, glabro en ambas caras, lóbulos 4, aovados a semiorbiculares, de $0.5 \mathrm{~mm}$ de largo, redondeados en el ápice, 
menudamente pubérulos por fuera, glabros por dentro, uno de ellos poco más largo, que los demás. Estambres 4, anteras sésiles en los senos de los lóbulos corolinos, anchamente elípticas de $0.2 \mathrm{~mm}$ de largo. Estilo incluso, de $1 \mathrm{~mm}$ de largo. Fruto en cápsula membranácea, bilocular de $1.5 \mathrm{~mm}$ de largo y 1.5$1.7 \mathrm{~mm}$ de ancho, pubescente sobre la mitad, circuncísil. Semillas amarillento a anaranjado-parduscas, ovadas a suborbiculares, menudamente tuberculadas en la cara dorsal, sin depresión cruciforme, la cara ventral con 4 surcos profundos en forma de " $x$ ", con hoyo subcentral.

Afin a Mitracarpus capitatus Lozada et Borhidi de Guerrero, que difiere de nuestra especie por tener corola más largo que los sépalos, tubo de 3 a 3.5 $\mathrm{mm}$ de largo, pubescente en ambas caras, lóbulos de 1.2 a $1.5 \mathrm{~mm}$ de largo, agudos, pubescentes en el interior. Parece también al Mitracarpus breviflorus A. Gray, por sus flores pequeñas, pero esta especie es diferente por ser una planta anual, con hojas de hasta $2.5 \mathrm{~cm}$ de largo y $6 \mathrm{~mm}$ de ancho, 1-nervias.

Etimología: El epiteto específico es de origen griego micranthos, que significa la flor pequeña.

Ejemplares estudiados: México, Oaxaca, Mpio. San Miguel Chimalapa: $3 \mathrm{~km}$ al SE de Congregación Benito Juárez, arroyo que baja de Cerro de la División, ca. $38 \mathrm{~km}$ en línea recta al NNE de San Pedro Tapanatepec; bosque mesófilo con Liquidambar, Quercus, Pinus, Tapirira mexicana, Ficus, Calophyllum etc. Coord.: $16^{\circ} 42^{\prime} \mathrm{N}, 94^{\circ} 07^{\prime} \mathrm{W}$, alt. $1100 \mathrm{~m} \mathrm{snm}$. Col:: Salomón Maya J. (603), 19.09.1984. (MEXU, MO). - Oaxaca, Entre Puerto Elígio a Comaltepec, km 147 entre Tuxtepec a Oax. S. Juárez. Col.: G. Martínez Calderón (418), 24.10.1965. - Oaxaca, Distrito Pochutla, Mpio. San Carlos Yautepec, San Miguel Chongo $1 \mathrm{~km}$ al $\mathrm{N}$ camino a Sosoltepec. Coord.: $16^{\circ} 0^{\prime} 57^{\prime \prime} \mathrm{N}, 95^{\circ} 58^{\prime} 3^{\prime \prime} \mathrm{W}$, alt. $510 \mathrm{~m} \mathrm{snm}$. Col.: Silvia H. Salas-Morales (3401) con M. Elorsa y A. Sánchez, 30.10.2000. - Oaxaca, Distrito Pochutla, Mpio. San Miguel del Puerto, Xadaní, $2.8 \mathrm{~km}$ W por la brecha a San Miguel del Puerto. Coord.: $15^{\circ} 56^{\prime} 36^{\prime \prime} \mathrm{N}, 96^{\circ} 5^{\prime} 43^{\prime \prime} \mathrm{W}$, alt. $610 \mathrm{~m}$ snm. Col.: Javier F. Castrejón R. (909) con E. Martínez S. y M. Elorsa C., 25.11.1999. - Oaxaca, Distrito Pochutla, Mpio. San Miguel del Puerto, 700 m de Santa María Xadaní. Col.: José Pascual (118), 19.10.2001.

Nota: En la Flora Mesoamericana solamente dos especies están tratatadas, que probablemente no representa la riqueza verdadera de este género, que esta manifestada en la Flora Mexicana (14 especies) y en la de las Antillas ( 15 especies).

Agradecimientos - Los autores expresan sus agradecimientos al Dr. Gerardo Adolfo Salazar, jefe del Departamento de Botánica, del Instituto de Biologia de la UNAM y al Dr. David Sebastian Gernandt, jefe del Herbario Nacional de México (MEXU) por su apoyo en crear condiciones favorables para este trabajo. 


\section{LITERATURA CONSULTADA}

Borhidi, A. (2012): Rubiáceas de México. Segunda y ampliada edición. - Akadémiai Kiadó, Budapest, $610 \mathrm{pp}$.

Borhidi, A. y Lozada, L. (2007): Estudios sobre Rubiáceas Mexicanas XII. El género Mitracarpus Zucc ex Schult. et Schult. f. (Spermacoceae) en México. - Acta Bot. Hung. 49: 81-98. doi: 10.1556/ABot.49.2007.1-2.3

Borhidi, A. y Martínez-Salas, E. (2012): Estudios sobre Rubiáceas Mexicanas XXXIX. Dos especies nuevas de Didymaea Hook. f. y una especie nueva de Mitracarpus Zucc. et Schult. et Schult. f. in Roem. et Schult. (Spermacoceae). - Acta Bot. Hung. 54: 73-79. doi: 10.1556/ABot.54.2012.1-2.8

Lorence, D. H. (2012): Mitracarpus Zucc. ex Schult. et Schult. f. in Roem. et Schult. - In: Davidse, G., Sousa, M., Knapp, S. y Chiang, F. (eds gen.): Flora Mesoamérica. IV(2): Rubiaceae, Cordiaceae, Boraginaceae, Lamiaceae. Universidad Nacional Autónoma de México, Missouri Botanical Garden, The Natural History Museum (London), pp. $16-37$. 